\title{
LA TERMINOLOGÍA DESDE EL PUNTO DE VISTA TEXTUAL: SELECCIÓN, TRATAMIENTO Y VARIACIÓN
}

\author{
Guiomar Elena Ciapuscio
}

\begin{abstract}
RESUMO: This article aims at contributing to the description and explanation of the relation between the degree of speciality of texts and the presence and treatment of terminology in them. The objective of the article is to demonstrate that the selection, treatment and variation of terms are conditioned by textual factors (basically ,functionality, users and text type). The corpus is composed by different textual types corresponding to texts of different degrees of speciality - abstract, paper, interview and press news - all of them dealing with the same scientific event. The results of the analysis lead to reliable statements of interest to special texts studies on the one hand, and to terminology and its practice, on the other.
\end{abstract}

PALAVRAS-CHAVE: terminologia e texto, discurso especializado, divulgação científica, tipologia textual, aplicações para o MERCOSUL.

El vuelco lingüístico en la disciplina Terminología ${ }^{1}$ que se ha registrado en los últimos años (Cabré, 1998; Cabré, 1999; Temmerman, 1997) ha abierto un campo de trabajo pleno de interesantes preguntas y cuestiones por resolver. Algunas de ellas son: la naturaleza del término, su comportamiento lingüístico en contextos reales de ocurrencia, su variación en el plano conceptual y formal, la relación del término con los aspectos textuales y discursivos. Este trabajo aspira a colaborar en la comprensión y explicación de la naturaleza y funcionamiento del término en relación con el texto, comprendido éste como una unidad lingüístico-comunicativa, resultado de determinada conceptualización por parte de un hablante y simultáneamente, oferta de interpretación para sus eventuales destinatarios. En este sentido, el presente trabajo continúa una línea de descripciones empíricas y reflexiones teóricas que aspiran a reunir los aportes de la Lingüística del Texto y la Terminología (Ciapuscio, 1997; Ciapuscio, 1999a; Ciapuscio, 1999b; Ciapuscio \& Otañi, 1998).

El propósito de este artículo es demostrar con fundamento empírico que la selección, el tratamiento y la variación de los términos están condicionados por factores de índole textual. La validación de esta hipótesis tiene consecuencias de orden teórico y metodológico para la Terminología y su práctica, por un lado, y por el otro, para los estudios sobre los textos de especialidad.

El marco teórico en el que se incluye este trabajo se alimenta de distintas procedencias: la lingüística del texto de origen germano, especialmente, la lingüística del texto especializado (Ciapuscio, 1993; Ciapuscio, 1994; Hoffmann, 1987; Schröder, 1991), la teoría comunicativa de la terminología (Cabré, 1998; Cabré, 1999) y la lexicología vertical (Wichter, 1994).

\section{ALGUNAS DEFINICIONES TEÓRICAS PREVIAS}

\footnotetext{
Guiomar Elena Ciapuscio é professora da Universidade de Buenos Aires

${ }^{1}$ A los efectos de facilitar la lectura, emplearé las mayúsculas para referirme a la disciplina Terminología, las minúsculas, para los términos, en tanto unidades lingüísticas.
} 


\section{El concepto de texto}

Os textos son objetos lingüístico-comunicativos complejos, que incluyen distintos niveles de análisis:

básicamente, el nivel funcional, el nivel situacional, el nivel temático, el nivel de estructuración lingüística y el nivel de formulación. W. Klein (1992) recupera inteligentemente el origen de la palabra texto para demostrar la complejidad del objeto e ilustrar las perspectivas de análisis que éste ofrece: proviene directamente del verbo latino texo, texui, textum que significa "tejer". El concepto de "texto" tiene, pues, el mismo origen que el griego techné y el sánscrito taksati: un tejido rico y ordenado con sentido. Ese tejido, como todo producto de la capacidad humana, puede estudiarse desde dos perspectivas: la perspectiva del proceso (la actividad de producir o comprender) y la del producto (el resultado de esas actividades). Además, el tejido puede interesar desde el punto de vista de la totalidad (el cómo, el para qué empleo el tejido) o desde el punto de vista del entramado puntual (la microestructura: cómo se articulan, cómo se conectan las partes menudas entre sí). El analista puede seleccionar, según sus objetivos de investigación, la complejidad del objeto o bien un nivel o conjunto de niveles en particular. Esta distinción analítica entre macroestructura y microestructura (van Dijk, 1977; van Dijk, 1980a; van Dijk, 1980b), sin embargo, no debe conducir a la interpretación de que se trata de aspectos desconectados entre así; por el contrario, resultados de investigación previos (Ciapuscio, 1993; van Dijk, 1985) han demostrado que esta relación es de mutuo condicionamiento, esto significa que los niveles superiores del texto determinan los aspectos microestructurales (distribución informativa, conexiones sintáctico-semánticas entre las oraciones, léxico y sintaxis) y viceversa, los rasgos microestructurales son elementos ineludibles a la hora de describir y explicar el objeto texto en el nivel global.

\section{Clases textuales}

Según la distinción clásica de la linguística textual debe distinguirse entre tipo y clase textual: clase textual se aplica a clasificaciones empíricas, tal cual son realizadas por los miembros de una comunidad lingüística, es decir, clasificaciones cotidianas que pueden mencionarse por medio de determinados lexemas condensadores del saber sobre determinada clase textual: por ejemplo, "esto es un cuento", "esto es un artículo", etc. Por el contrario, tipo textual se concibe como una categoría ligada a una teoría para la clasificación científica de textos ${ }^{2}$. Brinker brinda una definición, a mi juicio, precisa y completa de clase textual:

Las clases textuales son esquemas de acciones lingüísticas complejas, válidos convencionalmente, y pueden describirse como conexiones típicas de rasgos contextuales (situacionales), funcional-comunicativos y estructurales (gramaticales y temáticos). Se han desarrollado históricamente dentro de la comunidad lingüística y forman parte del saber cotidiano de los hablantes; si bien poseen un efecto normativo, facilitan por otro lado la tarea comunicativa, en tanto brindan a los participantes de la comunicación orientaciones más o menos fijas para la producción y recepción de textos. (p. 124, mi traducción).

La investigación sobre tipologías textuales ha demostrado que los textos se agrupan en clases a partir de rasgos internos y externos; una caracterización tipológica debe recurrir necesariamente a criterios internos y externos, debe, en resumidas cuentas, considerar simultáneamente diferentes niveles de análisis, que reúnen los aspectos macro y microestructurales (Ciapuscio, 1994; Heinemann \& Viehweger, 1991). Los centrales son: a) nivel funcional; b) nivel situacional; c) nivel temático; d) nivel de estructuración lingüística; e) nivel de formulación prototípica.

\section{El término}

\footnotetext{
${ }^{2}$ Esta distinción fue formulada inicialmente por H. Isenberg: "Utilizamos la expresión clase de texto como designación, concientemente vaga, para toda forma de texto, cuyas características puedan fijarse mediante la descripción de determinadas propiedades, no válidas para todos los textos, independientemente de si estas propiedades pueden concebirse teóricamente y de qué manera dentro del marco de una tipología textual. Utilizamos, en cambio, el término tipo de texto como designación teórica de una forma específica de texto, descrita y definida dentro del marco de una tipología textual." (Isenberg, 1987).
}

Organon, Porto Alegre, nº 26, 1998 
Los términos son unidades léxicas que se emplean preferentemente en marcos de especialidad pero que debido a la creciente alfabetización científico-tecnológica de la sociedad (Fourez, 1994) - trascienden esos marcos y suelen incorporarse en la comunicación cotidiana. En tanto unidades lingüísticas exhiben las características propias del léxico en su conjunto: diversidad de ópticas de análisis, variabilidad, selección y uso orientado a fines específicos. En cuanto a la clásica y cuestionada dicotomía entre palabra y término, considero que no puede postularse una distinción tajante entre estas unidades sino - a lo sumo - una diferencia de grado: en tanto los términos se definen en el marco de una disciplina científica y obtienen su valor del sistema terminológico de esa disciplina, su significado está más "controlado" que el de las unidades lingüísticas de uso cotidiano, no acotado a ámbitos de conocimiento especializado. Esto no significa de ningún modo negar la realidad de la variación formal y conceptual del término en la perspectiva sincrónica y diacrónica; la realidad de la variación terminológica se explica por el carácter intrínsecamente dinámico del conocimiento y del uso lingüístico.

La naturaleza lingüística y comunicativa de los términos hace insoslayable su descripción y explicación en sus contextos naturales de empleo: los textos. En este sentido, este trabajo aspira a contribuir a la comprensión del problema de la variación formal y conceptual del término desde la perspectiva teórica y metodológica de la lingüística del texto.

\section{La comunicación especializada: los grados de especialidad de los textos}

Definir la comunicación especializada es una tarea compleja en la cual intervienen necesariamente las concepciones teórico-epistemológicas acerca de lo que se considera un texto y en la que se hace preciso determinar y decidir qué nivel o niveles de la unidad textual se emplea como criterio definitorio (¿el tema o ámbito temático, la funcionalidad, los usuarios?). Una interesante discusión se encuentra en Schnitzer \& Fortanet, 1998.

Un ángulo importante del problema es la noción de "especializado". El adjetivo especializado revela el carácter gradual de la noción pues permite los cuantificadores del tipo "más/menos/algo/poco/muy". ¿Cómo determinar de manera analítica que un texto es más (o menos) "especializado" que otro? Evidentemente en esta decisión son ineludibles los factores situacionales como los propuestos por diferentes autores como L. Hoffmann (1998b) y W. Heinemann y D. Viehweger (1991): variables funcionales, sociales, situación comunicativa, objeto comunicativo. Cabe subrayar, sin embargo, que la mayoría de estos factores son asequibles a partir del análisis estructural y lingüístico y, por el otro, que es preciso arribar a una determinación del grado de especialidad de un texto a partir de la descripción lingüística del mismo. En otras palabras, la noción de especialidad debería poder definirse a partir de un estudio lingüístico y estructural de los textos. Hoffmann (1998a) considera que un acercamiento posible para determinar el grado de especialidad de un texto - en realidad él emplea el sintagma "niveles de abstracción" - es la presencia de terminología ${ }^{3}$. Argumento empírico en este sentido y en cuanto al grado de concentración del conocimiento especializado, a partir de la terminología y su variación, brinda M. Domènech (1997). En trabajos previos (Ciapuscio, 1999a; Ciapuscio, 1999b; Ciapuscio \& Otañi, 1998) he planteado un nuevo ángulo de análisis para el contraste del grado de especialidad de los textos - esencialmente me he detenido en la variación conceptual - sobre la base del esquema, instrumento para representar la información conceptual y formal del signo lingüístico, reformulado para el análisis y explicación del Léxico por S.Wichter. El grado de llenado de los esquemas conceptuales correspondientes a textos de distintos niveles de especialidad, por un lado, y la relación entre las "ramas" del esquema (vínculos de orden condicional y/o aditivo) brindan información lingüístico-estructural fehaciente para realizar afirmaciones sobre el grado de especialidad de un texto. En esta contribución me propongo avanzar en la delimitación teórica y metodológica del grado de especialidad de los textos, a partir de la ocurrencia terminológica y su análisis conceptual y formal en distintas clases de textos.

\footnotetext{
${ }^{3}$ Por la presencia de terminología y el tipo de sintaxis (más o menos libre) Hoffmann distingue cinco niveles de abstracción (de máximo a muy bajo) que pone en correspondencia con disciplinas y ámbitos sociales. La base empírica de su distinción, sin embargo, no se explicita (ver págs. 62-65).
} 


\section{EL CORPUS Y LA METODOLOGÍA}

En el artículo trabajaré con textos que se refieren al mismo suceso: un avance científico protagonizado a comienzos de 1997 por un grupo de investigadores argentinos. Se trata de un progreso en el conocimiento del melanoma humano; el núcleo conceptual del suceso es el siguiente: los investigadores demostraron que en los casos de melanoma, como había sido probado en otros cánceres (colon, mamas), se encuentra sobreproducida una proteína llamada SPARC. Los efectos de esta proteína son de dos órdenes: por un lado, fomentan las propiedades adhesivas e invasivas de las células malignas; por el otro, al formar una especie de barrera del tumor, impiden la acción defensiva de los neutrófilos. El grupo de investigación, aplicando técnicas de ingeniería genética, suprimió la producción de la proteína y logró impedir la formación de tumores y limitar la propagación de la enfermedad.

Este suceso - que tuvo repercusión en la comunidad científica internacional - fue comunicado a distintos destinatarios por medio de distintas clases textuales, propias de los ámbitos comunicativos involucrados. En primer lugar, el descubrimiento fue comunicado a los pares en una prestigiosa revista internacional Nature Medicine, bajo la forma de paper y su correspondiente abstract. Esta información, por su importancia científica y por la repercusión en la vida de las personas, trascendió el círculo experto y fue dada a conocer a públicos más amplios (legos y semilegos, cfr. Wichter, 1994) en la forma de noticias periodísticas y publicaciones en revistas de semidivulgación.

El corpus, por tanto, se compone de los siguientes textos, a los que adscribo un Nivel (N) de especialidad diferente en cada caso, sobre la base de parámetros funcionales y situacionales (Heinemann \& Viehweger, 1991). La totalidad de los textos tiene como función transmitir determinada información; en los textos especializados, además, se aspira a lograr la aceptación del resultado por parte de la comunidad científica. El tema principal en todos los casos lo constituye el mismo suceso científico. Difieren claramente en el nivel de situación: en el ámbito discursivo, en los usuarios de los textos y en el formato textual:

Paper y abstract ${ }^{4}$ : se trata de clases de textos del ámbito científico-académico, y corresponden a la comunicación entre pares; el suceso científico se ofrece en los formatos textuales propios de la comunicación en el nivel más alto de especialidad. Se analiza el abstract de manera pormenorizada y completa; del paper solo se toma el fragmento que condensa las conclusiones del trabajo y su inclusión en este estudio es parcial e ilustrativo de algunos nodos. Corresponden al N 1 de especialización.

Entrevista: se incluye en una revista de determinado ámbito académico pero se trata de una comunicación entre el científico (el entrevistado) y un público restringido, posiblemente con formación universitaria. Le adscribo el N 2, que podría etiquetarse provisoriamente como semidivulgación (Loffler-Laurian, 1983).

Textos periodísticos: comunicación del suceso al gran público, en periódicos argentinos de gran tirada. La información científica se debe contextualizar en el nuevo ámbito discursivo, dentro de los formatos textuales propios de ese ámbito: la noticia y la nota periodística. Incluyo estos textos en el N3, que corresponde a divulgación masiva.

En cuanto al aspecto metodológico, se trata de un trabajo de orientación empírica, de orden cualitativo. Los resultados son solo ejemplares y aspiran a aportar argumentos a favor de la hipótesis que guía mis trabajos y que ha sido enunciada en artículos anteriores respecto al mutuo condicionamiento entre los aspectos microestructurales y macroestructurales de los textos.

\section{Objetivos del estudio}

Este trabajo intenta responder los siguientes interrogantes:

1. ¿Cómo se transmite, desde el punto de vista terminológico, el mismo suceso a distintos destinatarios, diferenciados por su nivel de experticia?

2. ¿En qué medida las propiedades de las distintas clases textuales nos permiten explicar la selección y tratamiento de la terminología?

\footnotetext{
${ }^{4}$ Trabajo con la versión castellana de los textos, distribuida por los autores; la publicación se realizó en una revista de lengua inglesa (Nature Medicine, volume 3, number 2, february 1997).

Organon, Porto Alegre, nº 26, 1998
} 
3. ¿Qué implicaciones de orden conceptual en la oferta interpretativa acarrean los desplazamientos y el tratamiento de la terminología en los distintos N?

4. ¿Qué consecuencias de índole teórica pueden desprenderse del análisis textual y terminológico?

Para responder estas preguntas es preciso realizar un análisis minucioso de los textos que brinde información acerca de:

- Terminología que aparece en los distintos niveles de especialización N1, N2 y N3.

- Resultados contrastivos acerca de la posible comunidad total/parcial en la terminología empleada para comunicar el mismo suceso a distintos destinatarios.

- En qué medida y en qué grado de importancia la terminología (sea cual fuere) es objeto de procedimientos de tratamiento - parafrástico /no parafrástico -.

\title{
ANÁLISIS
}

\section{El suceso desde el punto de vista conceptual}

A fin de describir y analizar la realización terminológica en sus aspectos conceptuales y formales en el corpus, es preciso realizar en primer lugar una representación conceptual del suceso común, que constituye el tema textual (síntesis conceptual mínima) de los textos. Con este propósito, reproduzco en primer lugar el abstract, a partir del cual reconstruiré el suceso desde el punto de vista conceptual:

La supresión de la expresión de SPARC por la utilización de ARN antisentido anula la tumorogenicidad de células de melanoma humano

\begin{abstract}
La adquisición del potencial invasivo-metastásico es un evento clave en la progresión tumoral. Las glicoproteínas de la superficie celular y sus respectivos "ligandos" a la matriz han sido involucrados en este proceso. Recientes evidencias muestran que la glicoproteína segregada SPARC (Secreted Protein Acidic and Rich in Cysteine, en español: proteína segregada acídica y rica en cisteína) resulta altamente expresada en diferentes tejidos malignos. El presente estudio informa que la supresión de la expresión de SPARC en células de melanoma humano, lograda utilizando un vector de expresión antisentido, resulta en una significativa disminución in vitro de las capacidades adhesivas e invasivas de las células tumorales, y anula por completo la tumorogenicidad in vivo. Esta es la primera evidencia de que SPARC juega un rol clave en el desarrollo del fenotipo invasivo-metastásico del melanoma humano.
\end{abstract}

El suceso científico puede representarse mediante la siguiente proposición: ${ }^{6}$

La supresión de la proteína SPARC mediante un vector antisentido anula la tumorogenicidad de células de melanoma y limita la metástasis.

El suceso se construye sobre la base de los siguientes nodos conceptuales, vinculados entre sí por relaciones de distinto orden (De Beaugrande \& Dressler, 1981)

\footnotetext{
5 M.Fernanda Leda, Soraya Adris, Alicia Bravo, Claudia Kairiyama, Laura Bover, Yuti Chernajovsky, José Mordoh y Osvaldo Podhajcer. Nature Medicine, Volume 3, number 2, february 1997.

${ }^{6}$ La proposición coincide casi totalmente con el título del abstract.

${ }^{7}$ La propuesta de estos autores se enmarca en un enfoque procedural en el cual la coherencia del texto es una red, resultado de una combinación de conceptos y relaciones a partir de la interacción entre el material textual y su intérprete (sus conocimientos previos, creencias, valores, etc.); la red se compone de espacios de conocimiento con el tópico principal en su punto medio. Los conceptos pueden comprenderse como pasos en la construcción de la continuidad de sentido. Distinguen conceptos primarios y secundarios: dentro de los primeros diferencian cuatro clases: objetos (entidades conceptuales con identidad y características estables), situaciones (configuraciones de objetos relacionados Organon, Porto Alegre, n⿳0 26, 1998 
genésis y

\begin{tabular}{|c|c|c|c|}
\hline $\begin{aligned} & \text { progresión tumoral } \leftarrow \\
& \leftarrow \leftarrow\end{aligned}$ & $\begin{array}{l}\text { melanoma } \uparrow \\
\leftarrow \leftarrow\end{array}$ & $\begin{array}{l}\text { proteína SPARC } \rightarrow \\
\leftarrow \leftarrow\end{array}$ & $\begin{array}{l}\text { vector antisentido } \downarrow \\
\leftarrow \leftarrow\end{array}$ \\
\hline
\end{tabular}

(técnicas genéticas ${ }^{\circ}$ )

(neutrófilos \pm )

Los últimos nodos conceptuales, ${ }^{\circ}$ y \pm , están ausentes en el texto de mayor grado de especialización (se colocan aquí entre paréntesis y no serán considerados de manera específica en el análisis). El nodo ${ }^{\circ}$ aparece en los textos del N2 y N3; el nodo \pm , solo en los textos del N3. Las flechas $\leftarrow \leftarrow$ indican las relaciones entre los nodos principales, que se tipifican de acuerdo con la propuesta de los autores mencionados (así por ejemplo, entre melanoma y proteína SPARC hay un vínculo que puede tipificarse como "localización", propiedad conceptual que significa: "la proteína SPARC se encuentra en el melanoma"). El suceso nuclear está presente en la totalidad de los textos analizados, con mayor o menor nivel de elaboración y especificidad, propiedades que, de acuerdo con una de las hipótesis de este trabajo, dependen de las funciones, los usuarios y la clase de texto.

La primera pregunta que se intenta responder aquí es la siguiente: ¿Cómo se realizan lingüísticamente cada uno de estos nodos en los textos correspondientes a N1, N2 y N3? La respuesta a esta pregunta permitirá develar por un lado, qué terminología aparece en cada nivel, y por el otro, ofrecerá material lingüístico para determinar en qué medida esta terminología es sometida a procedimientos de tratamiento parafrástico o no parafrástico. Por último, permitirá ofrecer argumento lingüístico sólido para determinar el grado de especialidad de los textos.

En el análisis que sigue partiré, en todos los casos, del abstract que precede al artículo científico y comparte con él su título. Como corresponde a un abstract, se trata de un texto con un altísimo grado de densidad informativa, que condensa la información central del artículo.

\section{Nodo $\leftarrow$ - "Génesis y progresión tumoral"}

\section{N1 - Abstract}

Si se observa nuevamente el texto, puede verse la terminología destacada en cursiva. El nodo conceptual $\leftarrow$ está representado por una serie de términos, sintagmas y agrupamientos terminológicos que se refieren a distintos aspectos del nodo:

1. adquisición del potencial invasivo-metastásico

2. progresión tumoral

3. tumorogenicidad in vivo;

4. disminución in vitro de las capacidades adhesivas e invasivas de las células tumorales

5. desarrollo del fenotipo invasivo-metastásico del melanoma humano.

El nodo conceptual incluye dos momentos en la enfermedad: por un lado, la transformación de tejidos en tumores malignos y por el otro, la progresión (metástasis) del tumor ${ }^{11}$. Debido a que los textos de divulgación (N2 y N3) oscilan en recuperar el primero y el segundo momento, trato ambos momentos como un único nodo.

en sucesión en sus estados actuales), sucesos (ocurrencias que modifican una situación o un estado dentro de una situación) y acciones (sucesos que lleva adelante un agente con un propósito).

${ }^{8}$ Ubicación espacial de una entidad (ibidem, pág. 101).

${ }^{9}$ Lo contrario de equivalencia (= igualdad, similaridad, correspondencia), ibidem, pág. 102.

${ }^{10}$ En inglés "instance": un elemento de una clase, que hereda todas las cualidades no suprimidas de la clase. En este caso, el vector antisentido es una instancia o caso de técnica genética.

${ }^{11}$ Realizo esta diferenciación en el nodo conceptual sobre la base de un texto periodístico más actual en el que el investigador, responsable de este avance, explica su labor; reproduzco a continuación el fragmento relevante: 
Así, los términos, agrupamientos y sintagmas terminológicos se ordenan de acuerdo con esas dos etapas:

Primer momento, transformación

tumorogenicidad in vivo

Segundo momento, progresión

potencial invasivo-metastásico

progresión tumoral

capacidades adhesivas e invasivas de las células tumorales

fenotipo invasivo-metastásico del melanoma humano.

Para la realización lingüística del primer momento, el abstract trae el término tumorogenicidad. Para el segundo momento, tenemos mayor diversidad que refleja, por cierto, especificidades conceptuales: potencial invasivo-metastásico, y capacidades adhesivas e invasivas de las células tumorales, refieren a la capacidad potencial del tumor o células tumorales de generar metástasis; progresión tumoral puede considerarse un sintagma sinonímico de metástasis, esto es, el fenómeno en acto, en tanto que fenotipo invasivo-metastásico ${ }^{12}$ apunta a las características morfológicas de la configuración genética del melanoma. Los términos y sintagmas terminológicos que realizan lingüísticamente la configuración conceptual "génesis y progresión tumoral" expresan alta especificidad conceptual propia de un texto para pares (N1). El fenómeno se aborda en el texto desde las perspectivas estructural (fenotipo), potencial-funcional (potencial invasivo-metastásico) y procesual (progresión tumoral). Veamos ahora qué ocurre en los N2 y N3.

\section{N2 - Entrevista}

El nodo conceptual se realiza del siguiente modo:

la producción del melanoma

se bloqueó por completo el crecimiento de las células (tumorales) humanas dentro de ratones

Solo el segundo caso realiza de modo directo la transformación de tejidos en tumores malignos (etapa primera); tenemos aquí una paráfrasis que evita la terminología experta:

tumorogenicidad (in vivo) / crecimiento de las células (tumorales) humanas dentro de ratones.

El científico en la entrevista no hace ninguna referencia al segundo momento de la enfermedad, a la metástasis. Esto es consecuente con el avance principal enunciado en el abstract y el paper: "anula la tumorogenicidad in vivo".

N3 - Periódicos

En el N3, en cambio, aparece el término metástasis en ambos periódicos.

\section{La Nación:}

1. un equipo de investigadores logró demostrar cómo - mediante el bloqueo de un gen - se pueden destruir tumores cancerosos e impedir la formación de metástasis.

2. la propagación del melanoma humano

\footnotetext{
"Nuestro proyecto intenta desentrañar los caminos que recorren ciertos genes que actúan sobre el melanoma (cáncer de piel) y estudiar los modos en que el tumor pasa de una situación inicial de transformación maligna hacia lo que se llama progresión, que es la diseminación de metástasis" (La Nación, 11 de diciembre de 1999, "Premios internacionales a la ciencia argentina").

12 "Fenotipo: conjunto de las características morfológicas de un individuo referidas a determinado gen, que son un resultado de la interacción entre los factores genéticos presentes en sus células (genotipo) y la acción de los factores ambientales". (Diccionario Kapeluz de la Lengua Española); "Biol. Realización visible del genotipo en un determinado ambiente" (DRAE).

Organon, Porto Alegre, n⿳2 26, 1998
} 
Clarín

1. (titular) Estudian cómo controlar la expansión de ciertos tumores

2. lograron suprimir la producción de una proteína, que aparentemente favorece las metástasis (copete)

3. al suprimir la producción de una proteína, ciertas células cancerígenas no pueden fijarse a otros tejidos sanos del cuerpo. Esto impide la metástasis, o extensión de la enfermedad a otras partes del organismo. (Primer párrafo)

4. Tal activación del sistema inmune es vital en los casos de metástasis, en los cuales los tumores se hallan diseminados por todo el organismo y para los cuales las terapias tradicionales no alcanzan. (Párrafo 11)

Los periódicos exhiben un tratamiento similar del nodo conceptual. Tanto La Nación como Clarín privilegian el segundo aspecto del descubrimiento relativo a la metástasis pero, sin embargo, no preservan fielmente la información: mientras que en el paper y el abstract los científicos solo afirman que se ha "disminuido" la propagación, en los periódicos se sostiene que se "impide" la metástasis. En ningún caso se hace referencia a la anulación de tumorogenicidad, que es, en realidad, el resultado más contundente.

Ambos periódicos eligen el término más difundido metástasis o bien paráfrasis construidas a partir de palabras del léxico general: propagación, expansión, extensión, (los tumores) se hallan diseminados ${ }^{13}$. Cuando el procedimiento de tratamiento reformulativo se orienta en el aspecto dinámico del concepto, se eligen en todos los casos nominalizaciones de verbos de proceso, cuando se prefiere la óptica resultativa, un verbo de estado junto con un participio.

En Clarín, el término es objeto de numerosos procedimientos de tratamiento reformulativo parafrástico (Gülich \& Kotschi, 1995), a fin de explicitar su significado para el lego: el concepto se introduce en el titular mediante un sintagma de significado transparente, que no incluye terminología específica (expansión de ciertos tumores); a continuación, en el copete (o entradilla) aparece el término, sin tratamiento alguno, precedido de artículo definido, las metástasis; luego, en el primer párrafo, se introduce nuevamente el término y se realiza una operación reformulativa del mismo, en la cual el hablante selecciona el aspecto dinámico del concepto para su explicación(la metástasis, o extensión de la enfermedad a otras partes del organismo). Por último, hacia el final del texto, vuelve a incluirse el término seguido de una reformulación parafrástica que privilegia el aspecto resultativo de la noción (los casos de metástasis, en los cuales los tumores se hallan diseminados por todo el organismo). En suma, se incluye en el texto para el lego el término metástasis, y se lo define desde dos puntos de vista: como proceso y como resultado. Es evidente que este término ha trascendido el marco de la especialidad y que se encuentra ampliamente difundido en la población; sin embargo, el periodista opta por definirlo para asegurar la comprensión de su texto.

De lo expuesto puede concluirse, entonces, que el nodo conceptual $\leftarrow$ se encuentra explicitado en los $\mathrm{N} 1, \mathrm{~N} 2$ y N3, aunque con diferencias importantes en los aspectos conceptual y formal: en el abstract se observa un alto grado de especificidad conceptual, puesto que se distinguen claramente dos fases de la enfermedad: conversión en tumor y propagación. La segunda fase se enfoca desde diferentes perspectivas (estructural, potencial-funcional y procesual), las cuales se cristalizan en diferentes términos (fenotipo, tumorogenicidad, progresión tumoral); en ningún caso se presentan operaciones de tratamiento sobre los términos, puesto que se presupone en este nivel de especialidad conocimiento terminológico compartido por los pares.

En la entrevista, el científico solo se refiere al "crecimiento" de las células malignas, centrando el avance en la gestación de la enfermedad y preservando la fidelidad de la información original del paper. No emplea terminología sino que recurre a lenguaje cotidiano para la explicación del fenómeno; esta es una característica permanente en el discurso del especialista dirigido a los no especialistas, quien además recurre a distintos procedimientos didácticos (símiles, metáforas, etc.) para hacer más claro el texto.

En los textos periodísticos, en cambio, se tiende a focalizar un momento de la enfermedad, la propagación, posiblemente porque de este modo el impacto del texto es mayor. Sin lugar a dudas esto tiene consecuencias en la calidad de la información que se transmite. En cuanto a la terminología, solo aparece el término ya extendido al campo lego, metástasis, sobre el que el autor realiza operaciones de reformulación parafrástica basadas en lenguaje cotidiano: las reformulaciones, como se vio arriba, captan el aspecto dinámico y resultativo del fenómeno, aunque siempre desde el punto de vista del afectado, esto es, desde las consecuencias en la salud del enfermo y no de la enfermedad y su génesis en sí, como ocurre en el abstract. La perspectiva seleccionada por los textos periodísticos se funda, naturalmente, en el destinatario del texto.

\footnotetext{
${ }^{13}$ Es de destacar que no seleccionan la variante progresión, que configura un caso de palabra del léxico general y término en este dominio de conocimiento, hecho que explicita el mismo investigador (ver nota al pie 11).

Organon, Porto Alegre, nº 26, 1998
} 
Por último cabe destacar que el término como nombre, metástasis, no aparece en el texto de mayor grado de especialización; solo ocurre en sintagmas terminológicos bajo la forma de adjetivo: potencial invasivo-metastásico; fenotipo invasivo-metastásico, lo cual revela el alto grado de especificidad con que se trata el nodo en contraste con los textos periodísticos, en los que no aparece ninguna especificación conceptual.

\section{Nodo $\uparrow$, "melanoma"}

\section{N1 - abstract}

En el abstract (N1) este nodo aparece en el título y en diversos lugares del texto, realizado del siguiente modo:

1. La supresión de la expresión de SPARC por la utilización de ARN antisentido anula la tumorogenicidad de células de melanoma humano

2. la supresión de la expresión de SPARC en células de melanoma humano

3. Esta es la primera evidencia de que SPARC juega un rol clave en el desarrollo del fenotipo invasivo-metastásico del melanoma humano

Como puede observarse en los pasajes extractados, el término melanoma aparece en todos los casos acompañado del adjetivo especificativo humano; en ningún caso recibe tratamiento parafrástico. ${ }^{14}$

\section{N 2 - Entrevista}

- la lucha contra el cáncer de piel denominado melanoma.

- decidí retornar al trabajo con este gen pero en cáncer de piel y, específicamente, el melanoma

En el primer caso, el término se introduce mediante una definición denominativa que lo presenta como un hipónimo de cáncer de piel; en el segundo, también el recurso es su ordenación respecto del superordinado.

\section{N3 - Periódicos}

El tratamiento en el caso de los periódicos (N3) es algo más detallado:

La Nación:

la propagación del melanoma humano, uno de los tipos de cáncer más agresivos y cuya incidencia crece en el mundo a razón de un 4\% anual desde 1973.

Clarín:

Para eso utilizaron cultivos celulares de melanoma humano (el más serio de los cánceres de piel).

La Nación lo ubica dentro del superordinado mayor (cáncer) y brinda además información de tipo enciclopédica acerca de su peligrosidad e incidencia. Clarín también lo define como hipónimo de cáncer de piel y destaca su gravedad. En suma, en los textos de N3 el término melanoma se define y explica. La referencia a su peligrosidad y crecimiento estadístico refuerza la relevancia y el interés de la noticia.

\section{Nodo $\rightarrow$ "proteína SPARC"}

\footnotetext{
${ }^{14}$ Idéntica selección y tratamiento se observa en el paper.
} 
Este nodo es complejo: incluye la entidad o individuo "SPARC" y una propiedad del mismo, su "expresión" (producción, presencia, serían paráfrasis adecuadas) en tejidos malignos. Trato la entidad y la propiedad separadamente.

a) La entidad

La entidad referida tiene un nombre propio, una sigla, SPARC, que solo se explica en el texto de mayor nivel de especialidad; en los N2 y N3 se emplea sin ningún despliegue. Esto acarrea, evidentemente, consecuencias importantes en la oferta conceptual de los distintos textos. Veamos, en primer lugar, la realización de esta entidad en el abstract.

N1 - abstract

En primer lugar, se introduce el tema mediante la mención del superordinado: Las glicoproteínas de la superficie celular (y) sus respectivos "ligandos" a la matriz (...); solo a continuación se introduce mediante artículo definido (presuponiendo conocimiento previo) la glicoproteína específica:

la glicoproteína segregada SPARC (Secreted Protein Acidic and Rich in Cysteine, en español: proteína segregada acídica y rica en cisteína)

La sigla desplegada brinda información muy específica acerca de la glicoproteína, dirigida a los pares. La totalidad de las menciones siguientes se realizan mediante el recurso a la sigla:

(...) la supresión de la expresión de SPARC (...)

(...) es la primera evidencia de que $S P A R C$ juega un rol clave (...)

Las menciones sucesivas mediante el empleo de la sigla desnuda (nótese que ni siquiera se acompaña del nombre que designa la clase "glicoproteína") puede explicarse a partir de la máxima de concisión propia del discurso científico que se extrema en el caso de la clase textual abstract.

En el paper la selección y tratamiento son en gran medida coincidentes: la introducción de la entidad se realiza con la mención de la clase, la sigla y su despliegue - a lo que además se agregan denominaciones alternativas en el discurso de especialidad; las menciones subsiguientes se llevan a cabo - en todos los casos mediante la sigla desnuda:

La glicoproteína SPARC (proteína segregada, acídica y rica en cisteína, también lllamada BM 40, proteína $43 \mathrm{~K}$ y osteonectina) (...) Indica que SPARC podría ejercer una profunda influencia....

\section{N2 - Entrevista}

la proteína Sparc (que inhibiría la producción del melanoma - cáncer de piel), se obtuvo, por primera vez este gen: Sparc.

Como puede observarse, la sigla se emplea aquí como nombre propio, sin especificación, como si no incluyera contenido intensional. En el primer caso, la entidad es referida como "proteína" y se pierde consecuentemente información relevante acerca de la clase de proteína; en el segundo caso, Sparc se presenta a partir del gen que la produce. La glicoproteína es, en realidad, un producto del gen homónimo.

En los textos periodísticos (N3), la entidad se presenta mayormente como "la proteína Sparc", mediante la mención del superordinado mediato (y no el inmediato, "glicoproteína") y la sigla sin despliegue; como es usual en este nivel de divulgación, son recurrentes las operaciones reformulativas. Veamos en primer lugar, el periódico La Nación:

se centró en ) el estudio de una proteína denominada Sparc y su función en la propagación del melanoma humano (...) (párrafo 2)

Los investigadores comenzaron estudiando la presencia de la citada proteína en el melanoma humano. "Nos llamó la atención que la proteína Sparc, elaborada por las células tumorales siguiendo las instrucciones de un gen, estaba muy aumentada en los tumores de cáncer de piel" explica el doctor Podhajcer...

La introducción del individuo se realiza mediante artículo indefinido - presuponiendo desconocimiento , la mención del superordinado mediato y una acción de reformulación denominativa permite la introducción de la sigla (sin despliegue). En las menciones sucesivas, se elige el sintagma construido por artículo definido + superordinado mediato, acompañado o no de la sigla. Además, en la última mención a la entidad de este texto, se agrega información relevante acerca del origen de la (glico)proteína: el hecho de ser un producto de un gen.

Clarín:

Organon, Porto Alegre, n 26, 1998 
lograron suprimir la producción de una proteína, que aparentemente favorece las metástasis (copete)

Un equipo de científicos argentinos demostró que al suprimir la producción de una proteína, ciertas células cancerígenas no pueden fijarse a otros tejidos sanos del cuerpo. (Primer párrafo).

Lo que hicieron los investigadores dirigidos por el doctor Osvaldo Podhajcer fue manipular el gen responsable de la producción de una proteína conocida como SPARC. Esta sustancia impide que el sistema inmunitario ataque las células tumorales y además favorece su expansión.

"Cuando la SPARC se produce normalmente - explica Podhajcer - se forma una especie de barrera defensiva alrededor de las células tumorales que impide que los neutrófilos, un tipo de glóbulos blancos, reconozcan las células cancerosas y las ataquen". Los investigadores argentinos lograron comprobar que, cuando se suprime la producción de la proteína, los neutrófilos tienen libre acceso a las células enfermas y comienzan a atacarlas.

Como vemos en los fragmentos seleccionados, la entidad se introduce en los primeros pasajes del texto con el artículo indeterminado y con el superordinado mediato, como también ocurre en La Nación: una proteína. Solo bastante avanzado el texto, el periodista brinda mayores especificaciones acerca de esta entidad, clave en el suceso que se informa: una proteína conocida como SPARC. Como vemos, el recurso es - también como sucede en La Nación - apelar a una operación denominativa, propia del discurso de divulgación (Ciapuscio, 1993; Loffler-Laurian, 1983). La denominación permite las posteriores remisiones con el mero nombre propio (SPARC); también se observa en la mención siguiente el recurso a un semitérmino (Kornfeld, Blaisten, Mazer, \& Simoni, 1998), acompañado por un deíctico que garantiza la correcta interpretación referencial (esta sustancia). La carga conceptual de las denominaciones es, evidentemente, mucho menor que la presente en el discurso especializado.

b) "la expresión" de Sparc

La entidad "proteína Sparc" se acompaña en el corpus de una propiedad: la expresión; cuando hay melanoma, la proteína está "altamente expresada" o "producida" o "aumentada", selecciones léxicas que están condicionadas por el grado de especialidad del texto, como veremos en los ejemplos que siguen.

\section{N1 - Abstract}

- la glicoproteína segregada SPARC (...) resulta altamente expresada

- la supresión de la expresión de SPARC en células de melanoma humano

El lexema seleccionado para la realización lingüística de la propiedad es "expresión": altamente expresada y la expresión. ${ }^{15}$ El texto para el especialista no incluye actividades de tratamiento sobre estos ítems léxicos, al contrario de lo que ocurre en los $\mathrm{N} 2$ y N3, en los que se hace preciso explicar la génesis de esta propiedad y, para ello, se recurre a lexemas más transparentes para el semilego y lego.

\section{N2 - Entrevista}

- Cuando uno habla de sobreproducción de gen, en realidad habla de sobreproducción de RNA mensajero que es el mensaje de ese gen y la proteína que deriva de ese mensaje. (El gen es el molde a partir del cual se produce el RNA mensajero).

- Lo que se cuantifica es el RNA mensajero o la proteína (que es el producto de este gen).

Como se ha afirmado más arriba, el científico en la entrevista manifiesta una fuerte vocación didáctica; en este caso, en la explicación acerca del origen de la presencia abundante (expresión, en el N1) de la SPARC, se observa nuevamente la homologación gen=proteína pero con un distanciamiento (marcado por el conector en realidad, (Gülich \& Kotschi, 1995) : Cuando uno habla de sobreproducción de gen, en realidad habla de sobreproducción de RNA mensajero que es el mensaje de ese gen y la proteína que deriva de ese mensaje. Acto seguido, se define para el lego el concepto "gen" mediante una metáfora en la que evoca un dominio de conocimiento cotidiano ("molde" para producir RNA). En el segundo fragmento, se vuelve a insistir en la relación gen=proteína. Evidentemente, hay conciencia en el especialista de la mayor familiaridad del lego con el concepto "gen" y esta circunstancia es aprovechada de manera intensiva para la explicación.

${ }^{15}$ En el paper se emplea preferentemente sobreexpresión de SPARC.

Organon, Porto Alegre, $n^{\circ} 26,1998$ 
N3 - Periódicos

La Nación

"Nos llamó la atención que la proteína Sparc, elaborada por las células tumorales siguiendo las instrucciones de un gen, estaba muy aumentada en los tumores de cáncer de piel" explica el doctor Podhajcer

el ADN de las células tumorales ordena la producción de determinadas proteínas a través del ARN mensajero. "Nosotros podemos medir tanto el ARN mensajero, que es el producto directo del gen, como la proteína, que es un subproducto de éste - dice el investigador - . De modo que lo primero que demostramos fue que los melanomas humanos expresan cantidades aumentadas de esa proteína con respecto a los melanocitos normales, que todavía no se han transformado"

Este periódico apela también a la vinculación gen = proteína para explicar el origen de la sustancia y su expresión aumentada en caso de melanoma. La propiedad "alta expresión" se reformula en el N3 con la paráfrasis muy aumentada o cantidades aumentadas, de significado más transparente para el destinatario tipo. Clarín recurre, como vemos a continuación, a abundancia.

Ya con anterioridad diferentes estudios habían comprobado que los tumores más invasivos y malignos iban asociados a una abundancia de la proteína SPARC

De estos ejemplos puede concluirse que las selecciones lingüísticas de los periodistas para referir a la propiedad "expresión" en los niveles de especialidad 2 y 3 son apropiadas para un destinatario no especialista; por otra parte, en ambos niveles de divulgación se recurre a la relación estrecha gen = proteína (ausente en el discurso más especializado) a fin de explicar el suceso de manera adecuada para el lego.

\section{Nodo $\downarrow$ "vector antisentido"}

\section{N1 - Abstract}

(...) lograda utilizando un vector de expresión antisentido (...)

En el texto de N1, el sintagma terminológico que designa la técnica génica para bloquear la producción de la proteína SPARC se emplea sin ningún tipo de tratamiento reformulativo. En los textos de N2 y N3 no aparece este sintagma sino que en su lugar aparecen reformulaciones construidas a partir de expresiones de lenguaje cotidiano o de términos que han trascendido el marco de especialidad.

\section{N2 -Entrevista}

lo que hicimos fue diseñar una estrategia, por ingeniería genética, de bloqueo de la producción de este gen, haciendo una copia en espejo. Para ejemplificar: cada gen está formado por una secuencia dada de cuatro elementos a los que podemos denominar con las letras, A, B, C y D. Puestas en un orden arbitrario a lo largo, por ejemplo de 1000 casilleros, formarían un gen. Este ordenamiento posee un inicio y un fin. El inicio sería en la letra Nro. 1 y el fin, en la letra Nro. 1000. Lo que nosotros hicimos fue diseñar una molécula, de modo tal que la célula comenzara a leer desde 1000 y no desde 1. Le dimos la secuencia inversa, es decir: el espejo del otro.

El extenso fragmento, que se dedica a la explicación de la técnica, evita toda terminología; en su lugar, se tiende al empleo de locuciones cotidianas como copia en espejo, el espejo del otro que recuperan el sentido primario de la técnica; por otro lado, se recurre a la ejemplificación, para asegurar la comprensión.

N3 - Periódicos

La Nación

trabajando en cierta medida a ciegas, los científicos argentinos decidieron bloquear la producción de la proteína y observar qué ocurría.

"Supongamos que cada paso de la cadena metabólica se nombra con una letra del abecedario - ejemplifica gráficamente Podhajcer-. Si uno bloquea zeta, lo más probable es que no pase nada demasiado importante, 
porque el problema está en ce o de. Bueno, en este caso lo que hicimos fue bloquear algo que no sabíamos si era ce o zeta. Y era ce."

Clarín

Para reducir la cantidad de SPARC, por ejemplo, tuvieron que diseñar una molécula a medida, capaz de interferir en el proceso de fabricación de la proteína. Y bloquear su producción.

En el caso de La Nación se realiza una referencia genérica al bloqueo de la producción (sin especificar la técnica empleada); en Clarín se comprueba la ausencia de terminología y solo la presencia de molécula - como en N2 - término que ha traspasado los límites del discurso de especialidad hace tiempo. La explicación de la técnica es marcadamente más superficial que en N2, solo se transmite el concepto de bloqueo de producción de la proteína pero no se explica en detalle el "cómo".

\section{Conclusiones}

En primer lugar presento un cuadro contrastivo que sintetiza parcialmente los resultados del análisis.

\begin{tabular}{|c|c|c|c|}
\hline & N1 & $N 2$ & $N 3$ \\
\hline \multirow[t]{2}{*}{ Nodo $\leftarrow$} & tumorogenicidad; & $\begin{array}{l}\text { la producción de melanoma } \\
\text { el crecimiento de las células } \\
\text { tumorales }\end{array}$ & $\varnothing$ \\
\hline & $\begin{array}{l}\text { potencial invasivo-metastásico; } \\
\text { progresión tumoral; } \\
\text { capacidades adhesivas e } \\
\text { invasivas de las células } \\
\text { tumorales; } \\
\text { fenotipo invasivo-metastásico. }\end{array}$ & $\varnothing$ & $\begin{array}{l}\text { propagación } \\
\text { metástasis; }(\mathrm{LN})^{16} \\
\text { la expansión de ciertos } \\
\text { tumores; metástasis, } \\
\text { la extensión de la enfermedad, } \\
\text { los tumores se hallan } \\
\text { diseminados }(\mathrm{Cl}) \text {. }\end{array}$ \\
\hline Nodo $\uparrow$ & melanoma humano & $\begin{array}{l}\text { el cáncer de piel denominado } \\
\text { melanoma } \\
\text { en cáncer de piel, y, } \\
\text { específicamente, el melanoma }\end{array}$ & $\begin{array}{l}\text { melanoma humano, uno de los } \\
\text { tipos de cáncer (...) LN. } \\
\text { melanoma humano (el más } \\
\text { serio de los cánceres de piel). } \\
\text { Cl. }\end{array}$ \\
\hline Nodo $\rightarrow$ a) & $\begin{array}{l}\text { la glicoproteína segregada } \\
\text { SPARC (Secreted Protein } \\
\text { Acidic and Rich in Cysteine, en } \\
\text { español: proteína segregada } \\
\text { acídica y rica en cisteína) } \\
\text { SPARC } \\
\text { SPARC }\end{array}$ & $\begin{array}{l}\text { la proteína Sparc } \\
\text { este gen: Sparc. }\end{array}$ & $\begin{array}{l}\text { una proteína denominada } \\
\text { SPARC } \\
\text { la citada proteína } \\
\text { la proteína SPARC }(\mathrm{LN}) \\
\text { una proteína que }(. . .) \text { favorece } \\
\text { la metástasis, } \\
\text { una proteína, } \\
\text { una proteína conocida como } \\
\text { SPARC, } \\
\text { Esta sustancia } \\
\text { la SPARC } \\
\text { la proteína }(\mathrm{Cl})\end{array}$ \\
\hline
\end{tabular}

\footnotetext{
${ }^{16}$ LN, La Nación; Cl., Clarín.
} 


\begin{tabular}{|c|c|c|c|}
\hline Nodo $\rightarrow$ b) & $\begin{array}{l}\text { altamente expresada } \\
\text { expresión de SPARC }\end{array}$ & $\begin{array}{l}\text { sobreproducción de gen, } \\
\text { sobreproducción de RNA y de } \\
\text { proteína }\end{array}$ & $\begin{array}{l}\text { muy aumentada; } \\
\text { cantidades aumentadas; (LN) } \\
\text { abundancia de SPARC (Cl) }\end{array}$ \\
\hline Nodo $\downarrow$ & vector de expresión antisentido & $\begin{array}{l}\text { copia en espejo } \\
\text { una molécula }(\ldots) \text { espejo del } \\
\text { otro }\end{array}$ & $\begin{array}{l}\text { una molécula a medida, capaz } \\
\text { de interferir }(\ldots) \text { y bloquear su } \\
\text { producción }(\mathrm{Cl})\end{array}$ \\
\hline
\end{tabular}

Fig. 1

A partir de estos resultados es posible entonces esbozar algunas conclusiones respecto a los interrogantes planteados al comienzo de este trabajo (cfr. 3.).

Los textos analizados, destinados a transmitir el mismo suceso científico a distintos destinatarios, muestran que no hay coincidencia en la terminología que aparece en los textos especializados por un lado y los divulgativos por el otro.

En los textos de N1 se ha observado una nutrida presencia de terminología altamente especializada que explicita de manera clara la especificidad y elaboración de la información que se transmite a los pares, a los fines de que ésta sea evaluada y aceptada. Esta terminología no recibe tratamiento reformulativo puesto que se presupone su comprensión por los pares.

En los $\mathrm{N} 2$ y N3, por el contrario, los ámbitos discursivos y el tipo de destinatarios (semilegos y legos) determinan que se escoja terminología que ha trascendido los marcos de especialidad (metástasis, gen, proteína, molécula). Esta terminología - que conforma evidentemente una zona intermedia entre el llamado léxico especial y el general - , además, es sometida a procedimientos de tratamiento parafrástico (definiciones, explicaciones) y no parafrástico (secuencias que incluyen información enciclopédica) a fin de asegurar la comprensión del suceso por un público amplio. Las operaciones sobre los términos en el discurso más divulgativo producen una acentuada variación formal que incluso lleva a la equiparación de unidades que no identifican a la misma entidad en el mundo científico (gen=proteína). En los textos más especializados se observa una escasa variación formal; cuando ocurre - como en el caso de la entidad "SPARC" - sigue un esquema regular: primero, la introducción mediante la sigla desplegada y la inclusión en la clase particular mediante el superordinado específico; luego, las sucesivas menciones se realizan mediante la sigla desnuda, de acuerdo con los preceptos de economía y simplicidad del discurso especializado. Además, cabe explicitar que la variación denominativa y conceptual supera el ámbito del término y alcanza las combinaciones sintagmáticas (sobreexpresión de SPARC, en el paper; abundancia de la proteína, en el periódico).

La selección diferenciada de terminología y la variación denominativa que se observa en los textos divulgativos determinan evidentemente consecuencias importantes en la oferta conceptual para el lego. En el análisis de los nodos conceptuales específicos se han puesto de manifiesto los desplazamientos que provocan la selección y el tratamiento terminológico.

Desde el punto de vista teórico, los resultados de este análisis muestran que, por un lado, los factores de índole funcional y situacional (interlocutores, clase textual, ámbito discursivo) condicionan la selección, el tratamiento y los límites de la variación formal y conceptual de la terminología. Por otro lado, puede afirmarse que el ángulo terminológico provee de argumentos de peso para la tipificación de las clases de textos (abstract, noticia de divulgación científica) en el nivel de formulación (cfr. 1. Clases Textuales) y para la determinación de su grado de especialidad, a partir de fundamentos lingüísticos (ibidem, La comunicación especializada). En efecto, se ha podido demostrar que la selección terminológica difiere de manera esencial en el N1 y en el N2 y N3: terminología altamente especializada sin tratamiento ocurre en el N1 mientras que la terminología extendida, acompañada de diversos procedimientos de tratamiento, aparece en los niveles divulgativos.

Desde el punto de vista de las aplicaciones y del trabajo terminográfico, el papel esclarecedor de los factores de orden textual en la terminología tiene consecuencias: señala con claridad la necesidad de reflexionar y realizar un análisis de base textualista sobre la selección de las fuentes, en consideración de los usuarios y finalidad del producto o aplicación por construir. Es evidente que la inclusión de los resultados de la investigación sobre textos de especialidad y su vinculación esencial con la terminología redundará en la calidad de los productos terminográficos. 


\section{BIBLIOGRAFÍA}

CABRÉ, T. Elementos para una teoría de la terminología: hacia un paradigma alternativo. In: El lenguaraz, 1, 1998.

CABRÉ, T. Hacia una teoría comunicativa de la terminología: aspectos metodológicos. In: Revista Argentina de Lingüística, 15, 1999.

CIAPUSCIO, G. E. Wissenschaft für den Laien: Untersuchungen zu populärwissenschaftlichen Nachrichten aus Argentinien. Bonn: Romanistischer Verlag, 1993.

. Tipos Textuales. Buenos Aires: Eudeba, 1994.

. Los científicos explican: la reformulación del léxico experto en la consulta oral. In: Cadernos do $\quad I L, 18,1997$.

.Clases de textos y terminologías: la variación vertical del término en sus contextos de uso. In: Actas de las I Jornadas Terminología y Mercosur: Recursos léxicos para la terminología. 1999a.

$15,1999 \mathrm{~b}$.

.Variación conceptual y grado de especialidad de los textos. Revista Argentina de Lingüística,

\& OTAÑI, I. La noción de esquema y la descripción del significado. VI Simposio

Iberoamericano de Terminología, La Habana, Cuba, 1998.

DE BEAUGRANDE, R., \& DRESSLER, W. Einführung in die Textlinguistik. Tübingen: Niemeyer, 1981.

DOMÈNECH, M. Unitats dee coneixement i textos especialitzats: primera proposta d'analisi. Tesis de maestría no publicada, Universidad Pompeu Fabra, Barcelona, 1997.

FOUREZ, G. Alfabetización científica y tecnológica. Buenos Aires: Ediciones Colihue, 1994.

Gülich, E., \& Kotschi, T. Discourse Production in Oral Communications. In: U. Quasthoff . Aspects of Oral Communication . Berlin/New York: de Gruyter, 1995.

HEINEMANN, W., \& VIEHWEGER, D. Textlinguistik: eine Einführung. Tübingen: Niemeyer, 1991.

HOFFMANN, L. Fachsprachen, Instrument und Objekt. Leipzig: Enzyklopädie, 1987.

HOFFMANN, L. Característiques dels llenguatges d’especialitat. In: J. Brumme. Llenguatges d'especialitat. Barcelona: Institut Universitari de Lingüística Aplicada, 1998a.

HOFFMANN, L. L'enfocament textual en la recerca sobre els llenguatges d'especialitat. In: J. Brumme (Ed.), Llenguatges d'especialitat. Barcelona: Institut Universitaari de Lingüistica Aplicada, 1998b.

ISENBERG, H. Cuestiones fundamentales de tipología textual. In: E. Bernárdez, Lingüística del Texto. Madrid: Arco Libros, 1987.

KORNFELD, L., BLAISTEN, N., MAZER, V., \& SIMONI, M. E. Caracterización del funcionamiento de los "semitérminos" en el vocabulario especializado. Ponencia presentada en el VI Simposio Iberoamericano de Terminología, La Habana (Cuba), 1998.

LOFFLER-LAURIAN, A. M. Typologie des discours scientifiques: deux approches. Etudes de Linguistique Appliquée, 51, 1983.

LOFFLER-LAURION, A. M. Typologie des discours scientifiques: deux approches". Études de Linguistique Appliquée, 51, 1983.

SCHNITZER, J., \& FORTANET, I. Lengua para fines específicos y lenguaje de especialidad: Algunas consideraciones conceptuales. In: I. Vázquez Orta \& I. Guillén Galve, Perspectivas Pragmáticas en Lingüística aplicada. Zaragoza: ANUBAR, 1998.

SCHRÖDER, H. Subject-oriented Texts: Languages for Special Purposes \& Text Theory. Berlin: Walter de Gruyter, 1991.

TEMMERMAN, R. Questioning the univocity ideal. The difference between socio-cognitive Terminology and traditional Terminology. In: Hermes, Journal of Linguistics, 18, 51-90, 1997.

VAN DIJK, T.Texto y Contexto (Semántica y pragmática del discurso). Madrid: Cátedra, 1997.

VAN DIJK, T. Macrostructures. Hillsdale, N.J.: Lawrence Erlbaum Publishers, 1980a.

VAN DIJK, T. Textwissenschaft: eine interdisziplinäre Einführung. Tübingen: Niemeyer, 1980b.

VAN DIJK, T. Semantic Discourse Analysis. In: VAN DIJK, T. Handbook of Discourse Analysis . New York: Academic Press, 1985.

WICHTER, S. Experten-und Laienwortschätze. Umriss einer Lexikologie der Vertikalität. Tübingen: Niemeyer, 1994. 